\title{
QUALIFICAÇÃO DA BIOMASSA EM POVOAMENTOS FLORESTAIS DE Pinus taeda
}

\author{
Juliana Ceccato Ferreira ${ }^{1 *}$, Thielly Schmidt Furtado Stähelin ${ }^{2}$, Marina Valin $^{3}$, Martha Andreia Brand ${ }^{4}$, \\ Graciela Inês Bolzon de Muñiz ${ }^{5}$ \\ ${ }^{1 *}$ Universidade Federal de Viçosa, Pós-Graduação em Ciência Florestal, Viçosa, Minas Gerais, Brasil - cf.juliana@ yahoo.com.br \\ ${ }^{2}$ Departamento Nacional de Infraestrutura de transportes, Brasília, Distrito Federal, Brasil - thiellysf@ hotmail.com \\ ${ }^{3}$ Suzano Celulose e Papel, Mucuri, Bahia, Brasil - marina-valin@ florestal.eng.br \\ ${ }^{4}$ Universidade do Estado de Santa Catarina, Departamento de Engenharia Florestal, Lages, Santa Catarina, Brasil - martha.brand@udesc.br \\ ${ }^{5}$ Universidade Federal do Paraná, Departamento de Ciências Florestais, Curitiba, Paraná, Brasil - gbmunize@ufpr.br
}

Recebido para publicação: 06/05/2014 - Aceito para publicação: 13/05/2016

\begin{abstract}
Resumo
O uso múltiplo das florestas plantadas pode aumentar a disponibilidade da biomassa destinada a sistemas de geração de energia. Para intensificar o potencial energético dessa fonte é necessário controlar propriedades como o teor de umidade e poder calorífico, que influem diretamente na capacidade energética do combustível. Neste contexto, o trabalho buscou avaliar a variação do teor de umidade e poder calorífico em acículas, galhos, copas e cascas de Pinus taeda em diferentes idades; verificar a relação entre o teor de umidade e o poder calorífico líquido; e definir um modelo de regressão que melhor explique o comportamento do poder calorífico líquido. Para a análise foi aplicado um delineamento experimental inteiramente casualizado, com arranjo fatorial contendo quatro componentes de árvores em quatro idades de Pinus taeda. Nos resultados, o modelo selecionado apresentou apenas o teor de umidade como variável independente; observou-se elevada correlação negativa entre teor de umidade e poder calorífico líquido, além de diferença significativa destas variáveis para todos os componentes e idades. As cascas em diferentes idades e galhos a partir dos 14 anos de idade são os componentes mais indicados para geração de energia.

Palavras-chave: Resíduos florestais; teor de umidade; eficiência energética.
\end{abstract}

\begin{abstract}
Qualification of biomass in forest stands of Pinus taeda. The multiple use of planted forests can increase the availability of forest biomass for energy generation systems. To increase its potential energy is necessary to control properties such as moisture content and calorific value, which directly influence the energy capacity of fuel. In this context, this paper attempts to evaluate the variation of moisture content and calorific value of needles, branches, canopies and barks of Pinus taeda in different ages; to investigate the relationship between the moisture content and the net calorific value; and to define a regression model that best explains the behavior of the net calorific value. For the analysis was applied a completely randomized design with factorial arrangement with four components of trees in four ages of Pinus taeda. In the results, the model selected had only moisture content as independent variable; there was a high negative correlation between moisture content and net calorific value, and significant difference of these variables for all components and ages. Barks at different ages and branches from 14 years of age are the most suitable components for power generation.

Keywords: Forest residue; moisture content; energy efficiency.
\end{abstract}

\section{INTRODUÇÃO}

A partir da década de 1970, as crises energéticas atreladas ao preço do petróleo e as novas concepções industriais e ambientais impulsionaram a busca por fontes energéticas renováveis utilizadas como auxílio para atender à demanda de energia das novas indústrias.

Promover a utilização da biomassa residual e de subprodutos gerados na agricultura, atividades silviculturais e humanas permitem, ao mesmo tempo, expandir a capacidade de produção da bioenergia e reduzir a quantidade de resíduos que constitui um problema ambiental para a sociedade moderna. Os resíduos, que muitas vezes tem um valor negativo, podem ser convertidos em uma fonte de receita, além de solucionar o seu problema de gerenciamento (OFFERMANN et al., 2011).

Em 2014 as florestas plantadas no Brasil atingiram 7,74 milhões de hectares, o que representa um crescimento de 1,8\% em comparação ao registrado em 2013. Deste total, os plantios de Pinus sp. se destacam na região Sul do Brasil, com 42,4\% plantados no Paraná e 34,1\% em Santa Catarina, representando as duas maiores 
áreas de plantio do Brasil, destinadas à produção de celulose, papel, madeira serrada ou reconstituída e biomassa para energia (INDÚSTRIA BRASILEIRA DE ÁRVORES (IBA), 2015).

Em 2014, o consumo brasileiro de madeira in natura proveniente de plantios florestais para uso industrial foi de 190,03 milhões de $\mathrm{m}^{3}$, representando um aumento de 2,6\% em relação ao consumo de 2013 (IBA, 2015), e dos quais se estimou a geração de 12,7 milhões de toneladas de biomassa residual (3,3 e 9,4 milhões de toneladas para pinus e eucalipto, respectivamente), passíveis de uso para geração de energia. Tal material teria um potencial energético equivalente ao de 2,6 milhões de toneladas de óleo cru (de origem petrolífera) ou 19 milhões de barris de petróleo.

A biomassa é a fracção biodegradável de produtos ou resíduos provenientes da agricultura, silvicultura, indústria ou residências (ANGELIS-DIMAKIS et al., 2011). Contém energia armazenada nos carboidratos que é liberada pelo processo de combustão e empregada para geração de calor, eletricidade e, também, para produzir combustíveis líquidos (etanol, biodiesel) e gasosos (produtos da pirólise rápida ou gaseificação). Além disso, a biomassa pode ser armazenada e a energia pode ser produzida à medida que for necessária, diferente de outras fontes, como a solar e eólica, que se caracterizam pela sua intermitência (FIORESE et al., 2014).

Entretanto, por causa de sua heterogeneidade (granulometria, densidade, teor de umidade e poder calorífico), os componentes das árvores apresentam diferenciação no potencial energético, o que acarreta em perdas na suficiência energética quando os mesmos não passam por seleção antes de sua destinação às caldeiras (BRAND et al., 2014a).

Logo, a fim de elevar a eficiência do material e torná-lo competitivo frente a outras fontes de energia é necessário controlar suas propriedades energéticas. Este controle é realizado por meio da análise e acompanhamento de variáveis como Teores de Umidade (TU) e de Cinzas (TC), densidade e Poder Calorífico (PC) (BRAND et al., 2014a), sendo o TU e o PC as variáveis que influem diretamente na capacidade energética do combustível (SOARES; HAKKILA, 1987).

O poder calorífico refere-se à quantidade de energia liberada na forma de calor pela combustão de uma unidade de massa de madeira, sendo expresso em calorias por gramas $\left(\mathrm{cal} . \mathrm{g}^{-1}\right)$ ou quilocalorias por quilograma $\left(\mathrm{kcal} \mathrm{kg}^{-1}\right)$. Pode ser expressa em Poder Calorífico Superior (PCS), Inferior (PCI) e Líquido (PCL), dependendo da consideração ou não do calor liberado pela condensação da água presente no combustível (SOARES; HAKKILA, 1987).

No PCS a combustão é efetuada a volume constante e a água formada durante a combustão é condensada, recuperando o calor derivado da mesma (BRIANE; DOAT, 1985). Refere-se à máxima energia liberada pelo combustível, considerando condições de queima ideais, nas quais o material está absolutamente seco. É altamente influenciado pela constituição química da madeira, principalmente pela lignina e extrativos (resinas, óleos-resinas, matérias graxas e óleos), que elevam o seu potencial (QUIRINO et al., 2005). Além disso, elevadas concentrações de carbono e hidrogênio aumentam o PCS, já o oxigênio o reduz, por ocupar os espaços vazios presentes nas células e não apresentar características energéticas.

A partir do PCS, desconta-se a energia gasta para evaporar o hidrogênio de constituição do combustível na forma de água, obtendo-se o PCI (NASCIMENTO, 2006). O PCL provém do PCI, descontando a energia consumida para evaporar a água presente no material recentemente abatido. Como o material utilizado raramente vai estar seco, sua energia potencial depende do teor de umidade existente, que representa a energia efetiva disponível ao sistema. Também é influenciado pelo teor de inorgânicos no material, os quais ocupam um determinado volume do mesmo, reduzindo a energia gerada por unidade de massa.

$\mathrm{O} \mathrm{TU}$, em porcentagem, indica a quantidade de água presente no material, apresentando a umidade em torno de 65 a $70 \%$ em base úmida, quando considerado o indivíduo recentemente abatido. Acima deste limite, calorias externas são necessárias para secar o material e permitir a combustão (QUIRINO et al., 2005). Para certas fornalhas, TU abaixo de $40 \%$ em base seca pode causar um processo de combustão explosivo que eleva a perda de energia para a atmosfera e aumenta a emissão de partículas de carbono. Já, TU superiores a $150 \%$ em base seca reduzem drasticamente a eficiência da queima, chegando a interromper o processo de combustão (SOARES; HAKKILA, 1987).

Assim, a determinação do TU é de grande importância, primeiramente por apresentar grande variação quando se relaciona às diferentes espécies, clima e armazenamento, dificultando o controle do processo de combustão. Diante do exposto, o presente trabalho teve por objetivo avaliar a variação do teor de umidade e poder calorífico em acículas, copas, galhos e cascas de Pinus taeda em diferentes idades; verificar a relação entre o teor de umidade e o poder calorífico líquido; e definir um modelo de regressão que melhor explique o comportamento do poder calorífico líquido.

\section{MATERIAL E MÉTODOS}

A quantificação da biomassa florestal foi realizada em povoamentos homogêneos de Pinus taeda, pertencentes à empresa Flobasa, do conglomerado Battistella, localizados em Bocaina do Sul, Santa Catarina, em 
idades de 10, 12, 14 e 24 anos referentes ao primeiro desbaste, terceira poda, segundo desbaste e corte raso, respectivamente. O método utilizado foi o método direto de quantificação e o método de árvore individual, com a seleção de cinco árvores por povoamento, provenientes de uma parcela de 10 x $10 \mathrm{~m}$ montada para cada idade. A seleção das árvores na parcela e a disposição das parcelas nos povoamentos foi feita de maneira aleatória.

Após a medição de diâmetro e altura total, as árvores foram derrubadas para remoção e pesagem das acículas, galhos, copa (parte do fuste com diâmetro inferior a $8 \mathrm{~cm}$ ) e de discos com $5 \mathrm{~cm}$ de espessura para remoção da casca, separadamente. Os discos foram retirados na base, altura do DAP, 25\%, 50\%, 75\% e 100\% da altura comercial (altura do fuste entre a base e o diâmetro mínimo de corte na árvore $-8 \mathrm{~cm}$ ). Amostras de cada material foram coletadas para realização das análises laboratoriais, no Laboratório de Química da Madeira, da Universidade do Estado de Santa Catarina (UDESC/CAV) e Laboratório de Análises de Combustíveis Automotivos (LACAUT), da Universidade Federal do Paraná (UFPR).

Primeiramente efetuou-se a picagem e determinação do TU (base úmida) através da Norma Brasileira Regulamentadora - NBR 14929, da Associação Brasileira de Normas Técnicas (ABNT) (2003); e do poder calorífico superior e líquido, com o uso da bomba calorimétrica, segundo o Deutsches Institut für Normung DIN 51900 (2000).

Para a análise estatística se considerou um experimento fatorial $4 \times 4$, sendo quatro componentes da biomassa (C) e quatro idades (I), com vinte repetições. Primeiramente foi realizada análise de variância dos dados - ANOVA, para as variáveis isoladas de componentes e idades, assim como para a interação entre eles. Quando a interação do componente com a idade foi significativa, procedeu-se o desdobramento da mesma, a fim de estudar as propriedades dos componentes dentro de cada idade.

Para os casos em que houve diferença significativa entre os dados foi aplicado o teste de média de Tukey, ao nível de 5\% probabilidade. Além disso, realizou-se a determinação da correlação existente entre TU e PCL por meio do cálculo do coeficiente de correlação de Pearson (r).

Na sequência, diferentes modelos de regressão foram testados a fim de avaliar o efeito do TU sobre o PCL, através do procedimento stepwise. Tal procedimento seleciona a variável independente que melhor se correlaciona com a variável dependente, e a compara com outras independentes por meio do teste de significância das mesmas pela análise de variância do teste $\mathrm{F}(\mathrm{p}<0,05)$.

A variável que apresentou o valor de F não significativo $(p>0,05)$ foi retirada da equação, permitindo que outra fosse adicionada ao modelo e submetida à análise. O modelo selecionado foi constituído apenas de variáveis independentes que explicaram as variações totais da variável dependente. Além de significativo pelo teste $\mathrm{F}$ ( $\mathrm{p}<$ 0,05), o modelo selecionado deve ter um elevado coeficiente de determinação $\left(\mathrm{r}^{2}\right)$ e baixo coeficiente de variação (CV) (MACHADO et al., 2008). As análises estatísticas foram feitas através do software Statistica 7.0.

\section{RESULTADOS}

Ao analisar a distribuição do PCS, PCL e TU para os componentes da biomassa em diferentes idades das árvores, não foi observada correlação entre PCS e PCL. O PCS foi influenciado principalmente pela constituição química dos componentes, os quais elevam o seu potencial energético e, por sua vez, o PCL calculado a partir do PCS varia em função do TU dos componentes, o que sempre o manterá com valores inferiores ao PCS. O PCL foi inversamente proporcional ao TU (Figura 1).

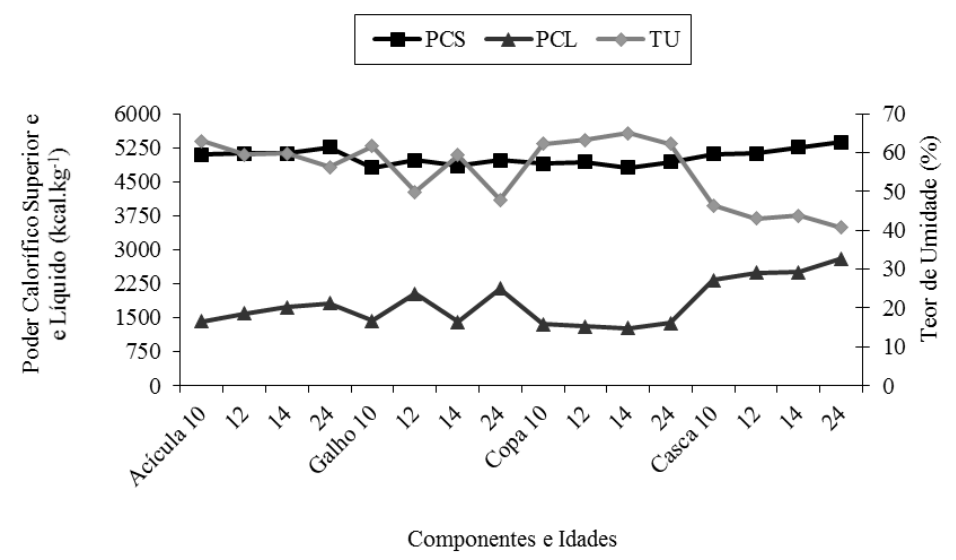

Figura 1. Distribuição do poder calorífico superior (PSC), poder calorífico líquido (PCL) e teor de umidade (TU) para os componentes acícula, galho, copa e casca nas idades de 10, 12, 14 e 24 anos para Pinus taeda.

Figure 1. Distribution of gross calorific value (GCV), net calorific value (NCV) and moisture content (MC) for the components needle, branch, canopy and bark at ages 10, 12, 14 and 24 years for Pinus taeda.

FLORESTA, Curitiba, PR, v. 46, n. 2, p. 269 - 276, abr. / jun. 2016.

Ferreira, J. C. et al.

ISSN eletrônico 1982-4688

DOI: $10.5380 /$ rf.v46i2.41208 
Para os galhos, os maiores valores de TU foram encontrados para as idades de 10 e 14 anos e os menores, para 12 e 24 anos. E para as copas o seu valor permaneceu constante. Em geral, os menores TU foram para as cascas, variando de 41-46\%. Os maiores valores variaram de 56-65\% para as copas, acículas e galhos de 10 e 14 anos (Figura 2).

Em relação à variável PCL, os maiores valores foram encontrados para as cascas nas quatro idades, variando de 2300 - $2800 \mathrm{kcal}_{\mathrm{kg}} \mathrm{kg}^{-1}$ e os menores para as copas nas quatro idades e galhos de 10 e 14 anos com variações de 1260 - $1800 \mathrm{kcal}_{\mathrm{kg}}{ }^{-1}$. O PCL de acículas e cascas teve um crescimento linear conforme o aumento em idade. Para as copas, o mesmo permaneceu constante para as diferentes idades e para os galhos, foi superior para 10 e 14 anos e inferior para 12 e 24 anos (Figura 2).

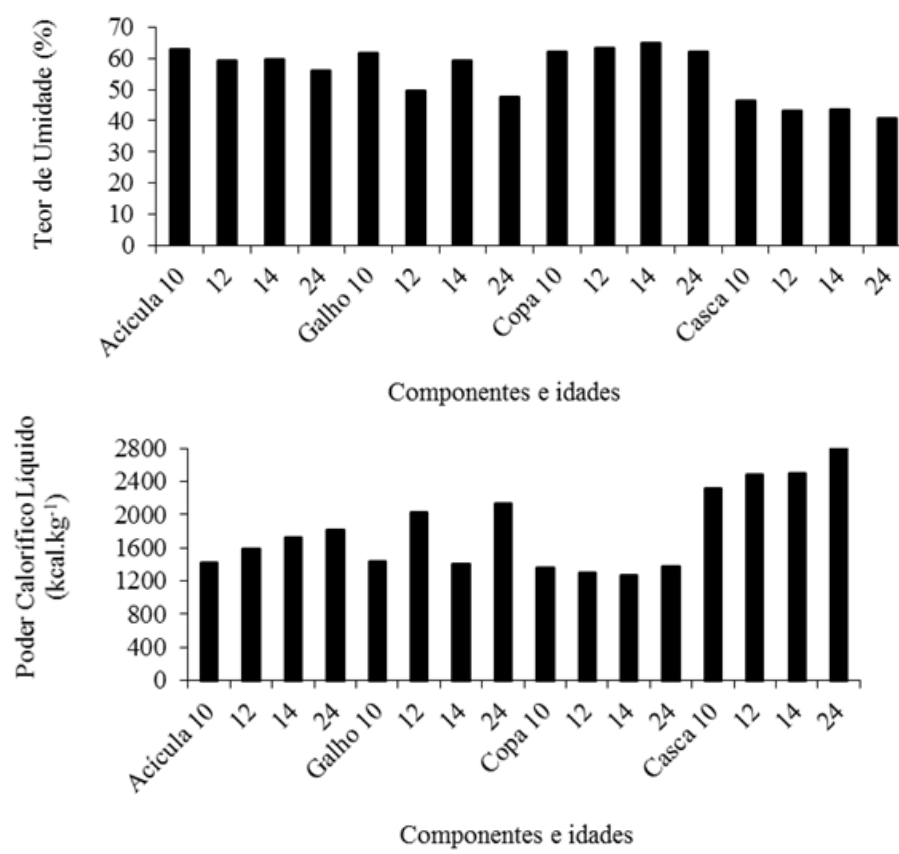

Figura 2. Variação das propriedades de Teor de Umidade (TU) e Poder Calorífico Líquido (PCL) para os componentes de árvores de Pinus taeda nas idades de 10, 12, 14 e 24 anos.

Figure 2. Variation of the properties of Moisture Content (MC) and net Calorific Value (NCV) for the components of Pinus taeda trees at ages 10, 12, 14 and 24 years.

Ao considerar isoladamente os componentes da planta (Tabela 1), nota-se que todas as variáveis apresentaram diferença significativa, o que não ocorreu para a idade, em que as diferenças não foram significativas para o TU e PCL.

Tabela 1. Análise de variância com o desdobramento para o poder calorífico superior (PCS), poder calorífico líquido (PCL) e teor de umidade (TU), para os diferentes componentes das árvores em diferentes idades para Pinus taeda.

Table 1. Analysis of variance with the development for the gross calorific value (GCV), net calorific value (NCV) and moisture content (MC), for the different components of trees at different ages for Pinus taeda.

\begin{tabular}{lccc}
\hline \multirow{2}{*}{ Fonte de Variação } & \multicolumn{3}{c}{ Quadrados Médios } \\
\cline { 2 - 4 } & PCS & PCL & TU \\
\hline Componente (C) & $5,5 \times 10^{5 *}$ & $5208713,0^{*}$ & $1368,7^{*}$ \\
Idade (I) & $9,1 \times 10^{4 *}$ & $638044,4^{\mathrm{NS}}$ & $164,3^{\mathrm{NS}}$ \\
C x I & $1,4 \times 10^{5 *}$ & $1278289,1^{*}$ & $338,5^{*}$ \\
\hline C d. I1 & $103757,7^{*}$ & $933270,6^{*}$ & $249,6^{*}$ \\
C d. I2 & $46960,4^{*}$ & $1335543,9^{*}$ & $375,0^{*}$ \\
C d. I3 & $237691,2^{*}$ & $1500939,1^{*}$ & $407,4^{*}$ \\
C d. I4 & $224929,7^{*}$ & $1809418,1^{*}$ & $449,9^{*}$ \\
\hline Resíduo & $7,8 \times 10^{3}$ & 19,3 \\
\hline * Diferença significativa pelo teste $\mathrm{F}(\mathrm{p}<0,05) ;{ }^{\mathrm{NS}}$ diferença não significativa $(\mathrm{p}>0,05) ; \mathrm{C}$ d. I1= Componentes dentro dos 10 anos de idade; & \\
\hline
\end{tabular}


Porém, a interação de componente com idade foi significativa para todas as variáveis estudadas, indicando que, conforme o componente da árvore e a idade da planta ocorrem alterações nas suas propriedades, em decorrência de modificações na atividade fisiológica, assim como na proporção de extrativos, lignina e no acúmulo de compostos inorgânicos. A partir do desdobramento dos dados da interação, observou-se que todas as propriedades diferiram entre os componentes da biomassa, dentro de cada idade das árvores.

Os valores médios de PCS, PCL e TU encontrados para todas as idades e componentes variaram entre

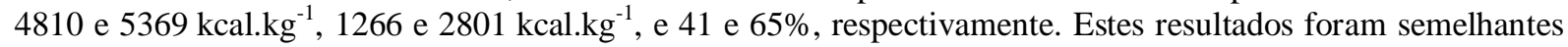
aos apresentados por Brand (2014a) em estudos sobre estocagem de biomassa florestal, os quais mantiveram

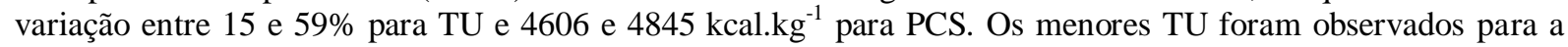
biomassa que permaneceu estocada por maior tempo (Tabela 2).

Tabela 2. Valores médios do Teor de Umidade (TU), Poder Calorífico Superior (PCS) e Poder Calorífico Líquido (PCL), para os componentes das árvores em diferentes idades para Pinus taeda.

Table 2. Average values of Gross Calorific Value (GCV), net Calorific Value (NCV) and Moisture Content (MC), to the components of the trees at different ages for Pinus taeda.

\begin{tabular}{|c|c|c|c|c|}
\hline \multirow{2}{*}{$\begin{array}{l}\text { Fonte de Variação } \\
\text { Idade }\end{array}$} & \multirow[b]{2}{*}{ Componente } & \multicolumn{3}{|c|}{ Médias } \\
\hline & & PCS (kcal.kg $\left.{ }^{-1}\right)$ & PCL (kcal.kg $\left.{ }^{-1}\right)$ & TU (\%) \\
\hline \multirow{4}{*}{10 anos } & Acícula & $5096 \pm 40^{\mathrm{a} *}$ & $1424 \pm 78^{\mathrm{b}}$ & $63 \pm 1^{\mathrm{a}}$ \\
\hline & Galho & $4812 \pm 241^{\mathrm{b}}$ & $1366 \pm 118^{b}$ & $62 \pm 2^{\mathrm{a}}$ \\
\hline & Copa & $4898 \pm 45^{\mathrm{ab}}$ & $1361 \pm 106^{b}$ & $62 \pm 2^{\mathrm{a}}$ \\
\hline & Casca & $5112 \pm 62^{\mathrm{a}}$ & $2323 \pm 95^{\mathrm{a}}$ & $47 \pm 1^{\mathrm{b}}$ \\
\hline \multirow{4}{*}{12 anos } & Acícula & $5121 \pm 54^{\mathrm{a}}$ & $1592 \pm 142^{\mathrm{bc}}$ & $60 \pm 3^{a}$ \\
\hline & Galho & $4976 \pm 69^{b}$ & $2029 \pm 739^{\mathrm{ab}}$ & $50 \pm 15^{\mathrm{ab}}$ \\
\hline & Copa & $4931 \pm 68^{b}$ & $1305 \pm 77^{\mathrm{c}}$ & $63 \pm 2^{\mathrm{a}}$ \\
\hline & Casca & $5116 \pm 62^{\mathrm{a}}$ & $2487 \pm 84^{\mathrm{a}}$ & $44 \pm 7^{\mathrm{b}}$ \\
\hline \multirow{4}{*}{14 anos } & Acícula & $5116 \pm 80^{\mathrm{a}}$ & $1728 \pm 263^{b}$ & $57 \pm 5^{\mathrm{b}}$ \\
\hline & Galho & $4844 \pm 81^{\mathrm{b}}$ & $1412 \pm 270^{\mathrm{bc}}$ & $59 \pm 3^{\mathrm{ab}}$ \\
\hline & Copa & $4810 \pm 179^{\mathrm{b}}$ & $1266 \pm 166^{\mathrm{c}}$ & $65 \pm 2^{\mathrm{a}}$ \\
\hline & Casca & $5262 \pm 93^{\mathrm{a}}$ & $2494 \pm 102^{\mathrm{a}}$ & $44 \pm 2^{\mathrm{c}}$ \\
\hline \multirow{4}{*}{24 anos } & Acícula & $5258 \pm 46^{\mathrm{b}}$ & $1812 \pm 87^{\mathrm{c}}$ & $56 \pm 2^{b}$ \\
\hline & Galho & $4977 \pm 48^{c}$ & $2146 \pm 245^{\mathrm{b}}$ & $48 \pm 4^{c}$ \\
\hline & Copa & $4935 \pm 32^{c}$ & $1374 \pm 145^{\mathrm{d}}$ & $62 \pm 3^{\mathrm{a}}$ \\
\hline & Casca & $5369 \pm 41^{\mathrm{a}}$ & $2801 \pm 112^{\mathrm{a}}$ & $41 \pm 2^{\mathrm{d}}$ \\
\hline
\end{tabular}

Médias seguidas pela mesma letra na coluna, dentro de cada componente não diferem significativamente pelo teste de médias de Tukey (p > $0,05) ; *$ Média \pm desvio padrão.

Na escolha da equação que melhor estimou o PCL a partir do TU (Tabela 3), optou-se pela equação linear, assim como o preconizado por outros autores, apesar de que todas as equações mantiveram valores de $\mathrm{r}^{2}$ próximos entre si. As equações cúbicas e quadráticas geram interpretações de alta complexidade e pouca aplicação prática.

Todos os componentes da biomassa analisados apresentaram redução do seu PCL a partir do aumento do TU (Figura 3). Isso é reforçado pela análise do coeficiente de correlação de Pearson (r) calculado para as variáveis TU e PCL, que apresentaram correlação negativa inferior a $(-0,86)$ para todos os componentes das árvores, indicando alta correlação entre elas.

Tabela 3. Modelos de regressão polinomial para o poder calorífico líquido (PCL) de resíduos florestais provenientes de povoamentos de Pinus taeda com idades de 10, 12, 14 e 24 anos.

Table 3. Polynomial regression models for the net calorific value (NCV) of forest residues from Pinus taeda aged $10,12,14$ and 24 .

\begin{tabular}{|c|c|c|c|c|}
\hline Componentes & Equação & $\mathbf{r}^{2}(\%)$ & CV (\%) & $\mathbf{F}$ \\
\hline Linear & $y=-55,0584 x+4821,5154$ & 94,91 & 25,9 & $1155,6^{*}$ \\
\hline Quadrática & $y=-0,1994 x^{2}-34,509 x+4311,8$ & 95,06 & 25,9 & $1092,9 *$ \\
\hline Cúbica & $y=0,0198 x^{3}-3,0776 x^{2}+99,9683 x+2.313,6165$ & 95,3 & 26,0 & $777,8 *$ \\
\hline Quarto grau & $y=-0,0004 x^{4}+0,1068 x^{3}-9,2783 x^{2}+289,5639 x+233,6666$ & 95,3 & 10,3 & $539,9 *$ \\
\hline
\end{tabular}

* Significativo pelo teste $\mathrm{F}(\mathrm{p}<0,05) ; \mathrm{y}=$ Poder calorífico líquido ( $\left.\mathrm{kcal} . \mathrm{kg}^{-1}\right) ; \mathrm{x}=$ Teor de umidade, base úmida $(\%)$. 


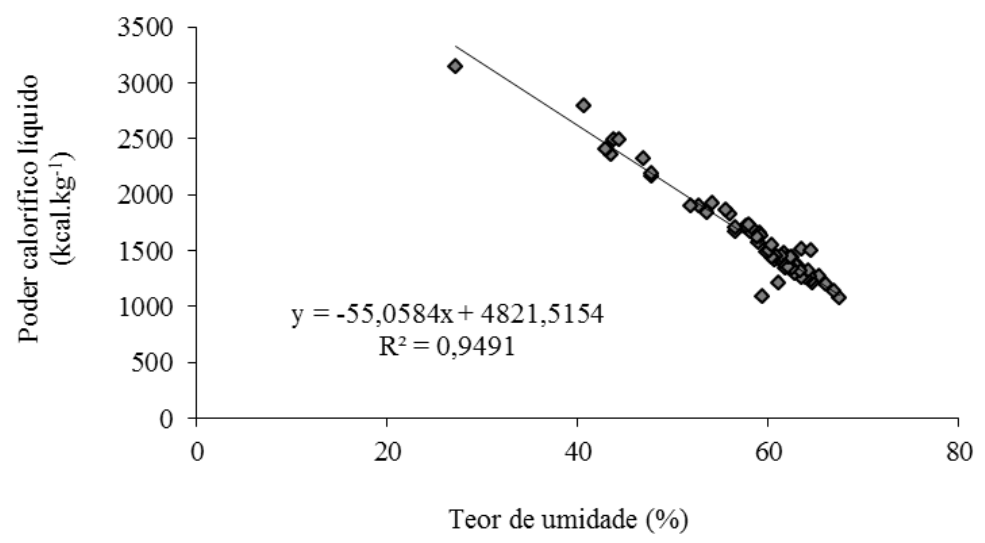

Figura 3. Dispersão dos dados de Poder Calorífico Líquido (PCL) em função do Teor de Umidade (TU) associado à curva de ajuste fornecida pelo modelo linear, para os resíduos florestais provenientes de povoamentos de Pinus taeda.

Figure 3. Dispersion of the Net Calorific Value (NCV) as a function of Moisture Content (MC) associated with the adjustment curve provided by the linear model for forest waste from stands of Pinus taeda.

\section{DISCUSSÃO}

A redução do TU para acículas e casca com o aumento em idade está relacionada com a atividade fisiológica das plantas. Plantas jovens, com maior atividade fisiológica, requerem maior disponibilidade de água para a condução dos nutrientes e dos compostos fotoassimilados. Em consequência, a redução do TU esteve associada à redução do PCL. Já o PCS não apresentou alterações em virtude da mudança do TU, visto que o PCS sofre influência de outras variáveis, em especial a constituição química (QUIRINO et al., 2005) (Figura 1 e Figura 2).

Para a idade de 10 anos as cascas apresentaram o maior PCL e o menor TU, diferindo significativamente dos demais componentes, os quais não diferiram significativamente entre si. Para a variável PCS, a casca também apresentou o maior valor, mas não diferiu significativamente das acículas e copa. Estas duas variáveis não diferiram dos galhos, que tiveram o menor PCS (Tabela 2).

Aos 12 anos de idade a casca manteve o maior PCL e menor TU, porém sem diferir significativamente dos galhos. Além disso, apresentou o maior PCS, não diferindo significativamente das acículas. A copa, por sua vez foi o componente que apresentou os menores PCS e PCL e o maior TU (Tabela 2).

Por estar em fase juvenil, a existência de elevada atividade fisiológica exige um maior TU do vegetal, que reduz em árvores adultas com menor metabolismo. Isto causa a redução do PCL e uniformidade do mesmo entre os diferentes componentes. Já o maior PCS para acículas e cascas pode ser explicado pelo maior teor de lignina (na casca) e extrativos (resina) presentes nos mesmos (MUÑIZ et al., 2014). Este comportamento foi semelhante para a idade de 14 anos, no qual a casca apresentou os maiores valores de PCS e PCL e menor valor para o TU, não diferindo significativamente apenas das acículas em relação ao PCS (Tabela 2).

Na idade de 24 anos, o menor valor de TU foi encontrado para a casca, seguido dos galhos, acículas e copa. E comportamento inverso foi observado para o PCL, ou seja, aos 24 anos, os galhos passaram a reduzir a atividade metabólica, o que reduz o TU, passando a ser inferior ao TU das acículas, que mantem a sua atividade fotossintética, do que em relação aos galhos que não diferiram significativamente entre si. E o maior valor foi encontrado para as copas, juntamente com as acículas. Porém, esta variação observada entre os componentes quanto ao PCL não é mantida para o PCS, em que o maior valor foi obtido para cascas seguidas das acículas, que não diferiram entre si. E o menor valor refere-se às copas que não diferiram dos galhos (Tabela 2).

Em parte, o comportamento do PCL nestes resultados pode ser explicado pela influência do TU sobre o mesmo, ou seja, quanto maior o teor de água presente no componente, maior a energia necessária para evaporála, reduzindo o PCL. Porém, outro fator que pode explicar as variações independentes de TU e PCL encontradas para as acículas e galhos está relacionado à possível influência negativa do teor de cinzas (compostos inorgânicos) presente nos materiais, que afeta o PCS e, consequentemente, o PCL. Porém, este não foi o objeto de estudo neste experimento.

Entre as idades de 10 e 14 anos, as cascas e acículas mantiveram os maiores valores de PCS indicando a maior presença de extrativos nestes componentes, quando comparados aos demais, principalmente a partir dos 14 anos. Porém, ao considerar as variáveis TU e PCL, que possuem influência direta sobre a capacidade energética dos materiais, as cascas e galhos passam a ter maior aplicabilidade. As cascas mantiveram com o 
passar dos anos um dos menores TU e o maior PCL. E os galhos passaram a apresentar estas mesmas características a partir dos 14 anos.

O menor TU presente nos galhos e casca pode ser explicado pela redução da atividade fisiológica em árvores adultas. Já as copas e acículas mantem o crescimento meristemático, mantendo o TU mais elevado. Além disso, a casca, constituída de células mortas, responsável pela proteção da madeira, tem mais influência da umidade do ambiente.

Ao considerar o efeito do TU no PCL pode-se definir, para efeitos práticos, que cascas em diferentes idades e galhos na idade de 24 anos são os mais indicados para a geração de energia, por apresentarem um dos menores TU e os maiores PCL.

Entre os dados analisados estatisticamente, variações de $300 \mathrm{kcal} . \mathrm{kg}^{-1}$ mostraram ser diferentes significativamente. Porém, para efeitos práticos esta diferença não distingue os materiais quanto a sua eficiência energética, permitindo que diferentes materiais sejam utilizados. Essa variação não influi no potencial da planta geradora permitindo um maior aproveitamento dos resíduos gerados na floresta.

No entanto, os valores de PCL podem sofrer um aumento a partir da redução do TU dos materiais. O PCL médio observado nestas condições de TU para as acículas, galhos, copas e casca das idades analisadas foi equivalente à 31,$8 ; 35,4 ; 27,1$ e 48,4\% do PCS dos componentes, respectivamente.

Já, o resultado observado na tabela 3 e figura 3 é condizente com a literatura. Furtado et al. (2012), ao trabalharem com a espécie Pinus taeda em diferentes idades, observaram tendências lineares ou quadráticas para interações semelhantes às estudadas neste trabalho. $\mathrm{O}$ modelo linear foi o modelo expresso por Lima et al. (2008) ao estudarem a influência do TU sobre o PCL para a espécie de Eucalyptus benthamii, com $\mathrm{r}^{2}$ de $99 \%$. O mesmo é preconizado por Vale et al. (2007) que utilizaram um modelo linear para estimar o PCL de resíduos florestais e agrícolas em função do TU.

Neste sentido, em virtude da influência do PCL pelo TU, recomenda-se o tratamento da biomassa, visando à melhoria da qualidade do combustível para geração de energia. De acordo com Brand et al. (2014ab), uma das alternativas é a estocagem, que permite a redução do TU do material, em determinado espaço de tempo, trazendo melhorias ao mesmo, de modo a gerar energia de forma eficiente.

\section{CONCLUSÕES}

- As características avaliadas (TU, PCS e PCL) variaram entre os componentes e idades das árvores de Pinus taeda.

- Ocorreu correlação negativa e significativa entre o TU e PCL para os componentes avaliados.

- O modelo de regressão polinomial linear foi o mais indicado para explicar as variações do PCL em função do TU, apresentando um $\mathrm{r}^{2}$ de $94,91 \%$.

- Cascas em diferentes idades e galhos a partir dos 14 anos de idade foram os resíduos que apresentam maior potencial energético.

- A partir dos dados obtidos é possível indicar a viabilidade de seleção dos componentes antes de seu uso nas caldeiras e realizar a estocagem dos mesmos, a fim de reduzir o teor de umidade elevar o poder calorífico líquido.

\section{AGRADECIMENTOS}

À empresa Flobasa, pertencentes ao conglomerado Battistella, pelo fornecimento do material utilizado no estudo. À Universidade do Estado de Santa Catarina (UDESC) e à Universidade Federal do Paraná (UFPR), pela realização das análises. À Coordenação de Aperfeiçoamento de Pessoal de Nível Superior (CAPES), pela concessão da bolsa.

\section{REFERENCIAS}

ANGELIS-DIMAKIS, A.; BIBERACHER, M.; DOMINGUEZ, J.; FIORESE, G.; GADOCHA, S.; GNANSOUNOU, E.; GUARISO, G.; KARTALIDIS, A.; PANICHELLI, L.; PINEDO, I.; ROBBA, M. Methods and tools to evaluate the availability of renewable energy sources. Renewable Sustainable Energy Reviews, v. 15, n. 2, p. 1182 - 1200, 2011.

ASSOCIAÇÃO BRASILEIRA DE NORMAS TÉCNICAS (ABNT). NBR 14929: Madeira - Determinação do teor de umidade de cavacos - Método por secagem em estufa. Rio de Janeiro: 2003.

BRAND, M. A.; MUÑIZ, G. I. B.; BRITO, J. O.; QUIRINO, W. F. Influência das dimensões da biomassa estocada de Pinus taeda L. e Eucalyptus dunni Maiden na qualidade do combustível para geração de energia.

FLORESTA, Curitiba, PR, v. 46, n. 2, p. 269 - 276, abr. / jun. 2016.

Ferreira, J. C. et al.

ISSN eletrônico 1982-4688

DOI: $10.5380 /$ rf.v46i2.41208 
Revista Árvore, v. 38, n. 1, p. 175 - 183, 2014a.

BRAND, M. A.; STÄHELIN, T. S. F.; FERREIRA, J. C.; NEVES, M. D. Produção de biomassa para geração de energia em povoamentos de Pinus taeda L. com diferentes idades. Revista Árvore, v. 38, n. 2, p. 353 - 360, $2014 b$.

BRIANE, D.; DOAT, J. Guide technique de la carbonisation: la fabrication du charbon de bois. AixenProvence: ÉDISUD, 1985. 180 p.

DEUTSCHES INSTITUT FÜR NORMUNG e. V. - DIN. DIN 51900: Determining the gross calorific value of solid and liquid fuels using the bomb calorimeter, and calculation of net calorific value. Berlin: 2000.

FIORESE, G.; CATENACCI, M.; BOSETTI, V.; VERDOLINI, E. The power of biomass: Experts disclose the potential for success of bioenergy Technologies. Energy Policy, v. 65, p. 94 - 114, 2014.

FURTADO, T. S.; FERREIRA, J. C.; BRAND, M. A.; NEVES, M. D. Correlação entre teor de umidade e eficiência energética de resíduos de Pinus taeda em diferentes idades. Revista Árvore, v. 36, n. 3, p. 577 - 582 , 2012.

INDÚSTRIA BRASILEIRA DE ÁRVORES (IBA). Indicadores de desempenho do setor nacional de árvores plantadas referentes ao ano de 2014. Brasília: IBÁ, 2015. 100 p.

LIMA, E. A.; ABDALA, E. M.; WENZEL, A. A. Influência da umidade no poder calorífico superior da madeira. Colombo: Embrapa Florestas, 2008, 3 p. (Comunicado Técnico, 220).

MACHADO, S. A.; AGUIAR, L. P.; FIGUEIREDO FILHO, A.; KOEHLER, H. S. Modelagem do volume do povoamento para Mimosa scabrella Benth. na região metropolitana de Curitiba. Revista Árvore, v. 32, n. 3, p. $465-478,2008$.

MUÑIZ, G. I. B.; LENGOWSKI, E. C.; NISGOSKI, S.; MAGALHÃES, W. L. E.; OLIVEIRA, V. T.; HANSEL, F. Characterization of Pinus spp needles and evaluation of their potential use for energy. Cerne, v. 20, n. 2, p. 245 - 250, 2014.

NASCIMENTO, S. M.; DUTRA, R. I. J. P.; NUMAZAWA, S. Resíduos de indústria madeireira: caracterização, consequências sobre o meio ambiente e opções de uso. HOLOS Environment, v. 6, n. 1, p. 8 - 21, 2006.

OFFERMANN, R.; SEIDENBERGER, T.; THRAN, D.; KALTSCHMITT, M.; ZINOVIEV, S.; MIERTUS, S. Assessment of global bioenergy potentials. Mitigation and Adaptation Strategies for Global Change, v. 16, $\mathrm{n}$. 1, p. 103 - 115, 2011.

QUIRINO, W. F.; VALE, A. T.; ANDRADE, A. P. A.; ABREU, V. L. S.; AZEVEDO, A. C. S. Poder calorífico da madeira e de materiais ligno-celulósicos. Revista da Madeira, n. 89, p. 100 - 106, 2005.

SOARES, R. V.; HAKKILA, P. Potencial energético dos resíduos de desbastes em plantações de Pinus taeda no estado do Paraná, Brasil. Revista Floresta, v. 17, n. 12, p. 73 - 94, 1987.

VALE, A. T.; GENTIL, L. V.; GONÇALEZ, J. C.; COSTA, A. F. Caracterização energética e rendimento da carbonização de resíduos de grãos de café (Coffea arabica, L) e de madeira (Cedrelinga catenaeformis), Duke. Cerne, v. 13, n. 4, p. 416 - 420, 2007. 